\title{
Uncommon case of pericardial effusion
}

Andrea D’Amato, Costantino Mancusi, Maria Viviana Carlino, Veronica Lio, Federica De Pisapia, Alfonso Sforza, Giovanni de Simone

Hypertension Research Center, Department of Translational Medical Science, Federico II University, Napoli, Italy

\begin{abstract}
We present the case of a 59-year-old patient with severe aortic stenosis, asymptomatic mild to moderate pericardial effusion and no major risk factors for poor prognosis. He underwent four-week course of non-steroidal anti-inflammatory drugs (ibuprofen $600 \mathrm{mg}$ TID) with no improvement of the effusion. After complete diagnostic work-up and examination, we discovered that he had a prostate cancer with bone metastasis. On the bone scintigraphy, there was particular involvement of ribs and sternum. We decided to treat our patient with an association of docetaxel and hormone therapy, after six months we observed a reduction in the pericardial effusion. Even in the presence of a patient without risk factor of poor prognosis, pericardial effusion can be the first sign of occult neoplasia.
\end{abstract}

\section{Introduction}

According to the current guidelines, in the clinical approach of pericardial disease we should evaluate the indicators of poor prognosis according with current guidelines. ${ }^{1}$ Even in patients without major risk factors, the evidence of pericardial effusion can be the only clinical sign of an occult neoplasia. ${ }^{2}$

Correspondence: Costantino Mancusi, Hypertension Research Center, Department of Translational Medical Science, Federico II University, via Pansini 5, 80131 Napoli, Italy.

Tel.: +39.081.7462013.

E-mail: africans@live.it

Key words: Pericardial disease; cancer; inflammation; echocardiography.

Acknowledgments: thanks to Albano G. for helping in the management of the patient.

Contributions: $\mathrm{AD}$ and $\mathrm{CM}$ conceived the paper and wrote the manuscript; MVC, LV, FD, AS and GDS contributed to the discussion and edited the manuscript.

Conflict of interest: the authors declare no potential conflict of interest.

Received for publication: 14 September 2016.

Accepted for publication: 14 December 2016.

This work is licensed under a Creative Commons Attribution NonCommercial 4.0 License (CC BY-NC 4.0).

CC Copyright A. D'Amato et al., 2017

Licensee PAGEPress, Italy

Italian Journal of Medicine 2017; 11:331-334

doi:10.4081/itjm.2017.775

\section{Case Report}

A 59-year-old man presented to our outpatient clinic. He reported fever, myalgia and non-productive cough associated with chest pain. The patient smoked about 20 cigarettes per day, had a history of severe aortic stenosis, type 2 diabetes and was seropositive for hepatits $\mathrm{C}$ virus. No other cardiovascular risk factors were known. He denied the abuse of illicit drugs and dental procedures in the past years. He took the following medications daily: acetylsalycilic acid 100 $\mathrm{mg}$, metformin $1000 \mathrm{mg}$ bid.

At the time of his presentation at the outpatient clinic, he was asymptomatic for angina or dyspnea, but he complained about sore throat. He referred normal physical activity without any symptom. On physical examination he presented normal temperature, with pulse rate of 80 beats per minute, blood pressure of $130 / 80 \mathrm{~mm} / \mathrm{Hg}$, respiratory rate of 18 breaths per minute, oxygen saturation of $98 \%$ in room air. He appeared well, the conjunctivas were pale, and he had no cervical lymphadenopathy. Upon chest examination, he presented with systolic murmur V/VI of the aortic site, reduction of S2 and lung field clear to auscultation bilaterally, absent jugular venous distention, normal peripheral pulses. There were no Osler's nodes, Janeway's lesions, splinter hemorrhages, or peripheral edema. The electrocardiogram showed sinus rhythm with normal PR and QT interval, normal axis orientation, normal repolarization, the absence of any sign of pericardial effusion and the absence of left ventricular (LV) hypertrophy.

The results of laboratory tests were remarkable only for the presence of mild hypochromic microcytic anemia with slightly elevated erythrocyte sedimentation rate and C-reactive protein (Table 1).

The chest X-ray showed clear lungs, heart and me- 
diastinum within normal limits. The echocardiogram revealed concentric LV remodeling with normal systolic function, severe aortic stenosis and mild to moderate pericardial effusion (max $1 \mathrm{~cm}$ in parasternal long axis view) with remarkable thickening of the pericardial in-layer (Figure 1). Based on clinical signs (pericardial chest pain, new evidence of pericardial effusion and modest elevation of inflammation markers) we issued diagnosis of subacute pericarditis.

Our patient had no major risk factors associated with poor prognosis for pericarditis, ${ }^{2}$ the clinical course was subacute (symptoms over several days without a clear-cut acute onset) and there was no evidence of large pericardial effusion or cardiac tamponade or heart failure. Empiric treatment with anti-inflammatory medications was therefore issued (ibuprofen $600 \mathrm{mg}$ TID and colchicine $1 \mathrm{mg}$ BID) and short-term follow-up after 1 week to assess response. ${ }^{3}$

After 1 week, no improvement of the pericardial effusion was observed, while the patient was still asymptomatic. Based on 2016 European Society of Cardiology (ESC) guidelines on pericardial disease, a complete screening for secondary causes of pericardial effusion was decided, including autoimmune and neoplastic disease. ${ }^{1,4}$ Result of this screening is reported in Table 2.

Due to high values of prostate-specific antigen (PSA) and free PSA the patient was referred to urology. Urologists found an increased prostate size, with asymmetric hard consistency of the entire peripheral region of the left lobe with indication to perform a

Table 1. Baseline laboratory investigation.

\begin{tabular}{lcc}
\hline Parameter & Values & Reference range \\
\hline Hemoglobin $(\mathrm{g} / \mathrm{dL})$ & 11.2 & $12-16$ \\
\hline HCT $(\%)$ & 35 & $33-45$ \\
\hline MCV $(\mathrm{fL})$ & 79 & $70-91$ \\
\hline MCHC $(\mathrm{g} / \mathrm{dL})$ & 24 & $23-33$ \\
\hline PLT $\left(\times 10^{3} / \mu \mathrm{L}\right)$ & 164 & $130-400$ \\
\hline White cell count $\left(\times 10^{3} / \mu \mathrm{L}\right)$ & 7.7 & $4.8-10.8$ \\
\hline Neutrophils $(\%)$ & 70 & $40-70$ \\
\hline Lymphocytes $(\%)$ & 20 & $20-45$ \\
\hline Monocytes $(\%)$ & 4 & $3-10$ \\
\hline Basophils $(\%)$ & 4 & $0-1.5$ \\
\hline Eosinophils $(\%)$ & 2 & $0-6$ \\
\hline ESR $(\mathrm{mm} / \mathrm{h})$ & 34 & - \\
\hline CRP $(\mathrm{mg} / \mathrm{dL})$ & 0.08 & $0-0.50$ \\
\hline Fibrinogen $(\mathrm{mg} / \mathrm{dL})$ & 332 & $160-350$ \\
\hline
\end{tabular}

$\mathrm{HCT}$, hematocrit; MCV, mean corpuscular volume; MCHC, mean corpuscolar hemoglobin concentration; PLT, platelets; ESR, erythrocyte sedimentation rate; CRP, C-reactive protein. prostate biopsy. Histological examination revealed an acinar adenocarcinoma, Gleason score 9, with invasion of the nerve trunks of small and medium caliber. He underwent also bone scintigraphy, which showed diffuse bone metastases, involving ribs in both chest walls. The tumor staging was T4N1M1 (Figure 2). The patient was referred to an oncology team for appropriate treatment: 6 cycles of docetaxel e hormone therapy treatment. ${ }^{5}$ No further in-depth analysis was decided for pericarditis.

Pericardial effusion and thickness was monitored every month, and a reduction during the radiotherapy was observed $(0.4 \mathrm{~cm}$ of posterior free space was measured in the same projection as in Figure 1), but after therapy the effusion did not improve further.

After 12 months, the patient did not develop any symptom of pericarditis again.

\section{Discussion and Conclusions}

Current guidelines suggests that further testing is unnecessary if the diagnosis of pericarditis is confirmed and there is no reason to suspect a specific cause. ${ }^{1}$

If a specific cause is suspected based on medical history, physical examination or laboratory findings that suggest a causative disorder (e.g., cancer or connective-tissue disease), appropriate additional evaluation is indicated. It is also known that the size of the effusion correlates with the prognosis. Moderate effusions, as in the presented case, are more common for specific etiologies such as bacterial and neoplastic conditions ${ }^{3,6}$ Paraneoplastic pericarditis is rare and the most common tumors with a pericardial involvement are lung cancer, breast cancer, malignant melanoma, lymphomas and leukemia. ${ }^{2}$ In the setting of pericarditis with pericardial effusion, prevalence of malignant or infectious etiologies ranges from 15 to $50 \%$ depending on the published series. ${ }^{7,8}$

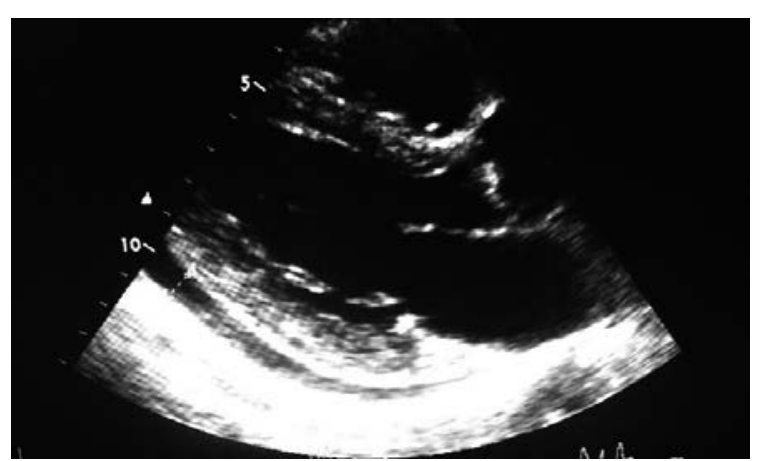

Figure 1. Parasternal long axis view with evidence of mild-moderate pericardial effusion. 
Table 2. Laboratory results for secondary causes of pericardial effusion.

\begin{tabular}{lcc}
\hline Parameter & Value & Reference range \\
\hline AFP $(\mathrm{ng} / \mathrm{mL})$ & 2.4 & $0-15$ \\
\hline CEA $(\mathrm{mcg} / \mathrm{L})$ & 5.3 & $0-4$ \\
\hline CA 19-9 $(\mathrm{U} / \mathrm{mL})$ & 22.9 & $0-37$ \\
\hline CA 15-3 $(\mathrm{U} / \mathrm{mL})$ & 14.8 & $0-50$ \\
\hline CA 125 $(\mathrm{U} / \mathrm{mL})$ & 2.9 & $0-35$ \\
\hline Ferritin $(\mathrm{ng} / \mathrm{ml})$ & 5 & $18-360$ \\
\hline B2-microglob $(\mathrm{ng} / \mathrm{mL})$ & 1732 & $660-2740$ \\
\hline PSA $(\mathrm{ng} / \mathrm{mL})$ & 55.7 & $0-4$ \\
\hline Rheumatoid factor $(\mathrm{U} / \mathrm{mL})$ & 9.19 & $0-15$ \\
\hline T.P.H.A. & Negative & Negative \\
\hline DSDNA-Ab $(\mathrm{U} / \mathrm{mL})$ & 8.60 & $<30$ \\
\hline ENA profile & Negative & Negative \\
\hline IgM CMV & Negative & Negative \\
\hline IgM HSV I/II & Negative & Negative \\
\hline IgM EBV & Negative & Negative \\
\hline Anti HIV & Negative & Negative \\
\hline IgM Brucella M. pneumoniae & Negative & Negative \\
\hline
\end{tabular}

There is limited literature on the timing of a malignant pericardial effusion in relation to the original malignancy. ${ }^{9}$ We observed within a group of patients with malignant pericardial effusion, that $50 \%$ of them presented with malignant pericardial effusion as the initial manifestation of the disease. ${ }^{3}$ In another group of patients, malignant pericardial effusion appeared approximately 11 months after initial diagnosis of malignancy. ${ }^{10}$

Management of such patients can be complex and may include, intrapericardial instillation of sclerosing and/or antineoplastic agents, systemic cytotoxic therapies, immunomodulators or surgical drainage procedures. ${ }^{11}$

We decided for watchful waiting, because the effusion had no hemodynamical impact and the patient was asymptomatic. Our hypothesis is that the pericardial effusion was connected to the systemic inflammatory response due to cancer bone metastasis on the ribs, although we did not exclude a pericardial metastasis, which required a biopsy. Our strategy was acceptable, being also confirmed by the partial reduction in the effusion during oncological therapy. The clinical course could support our decision. ${ }^{12}$

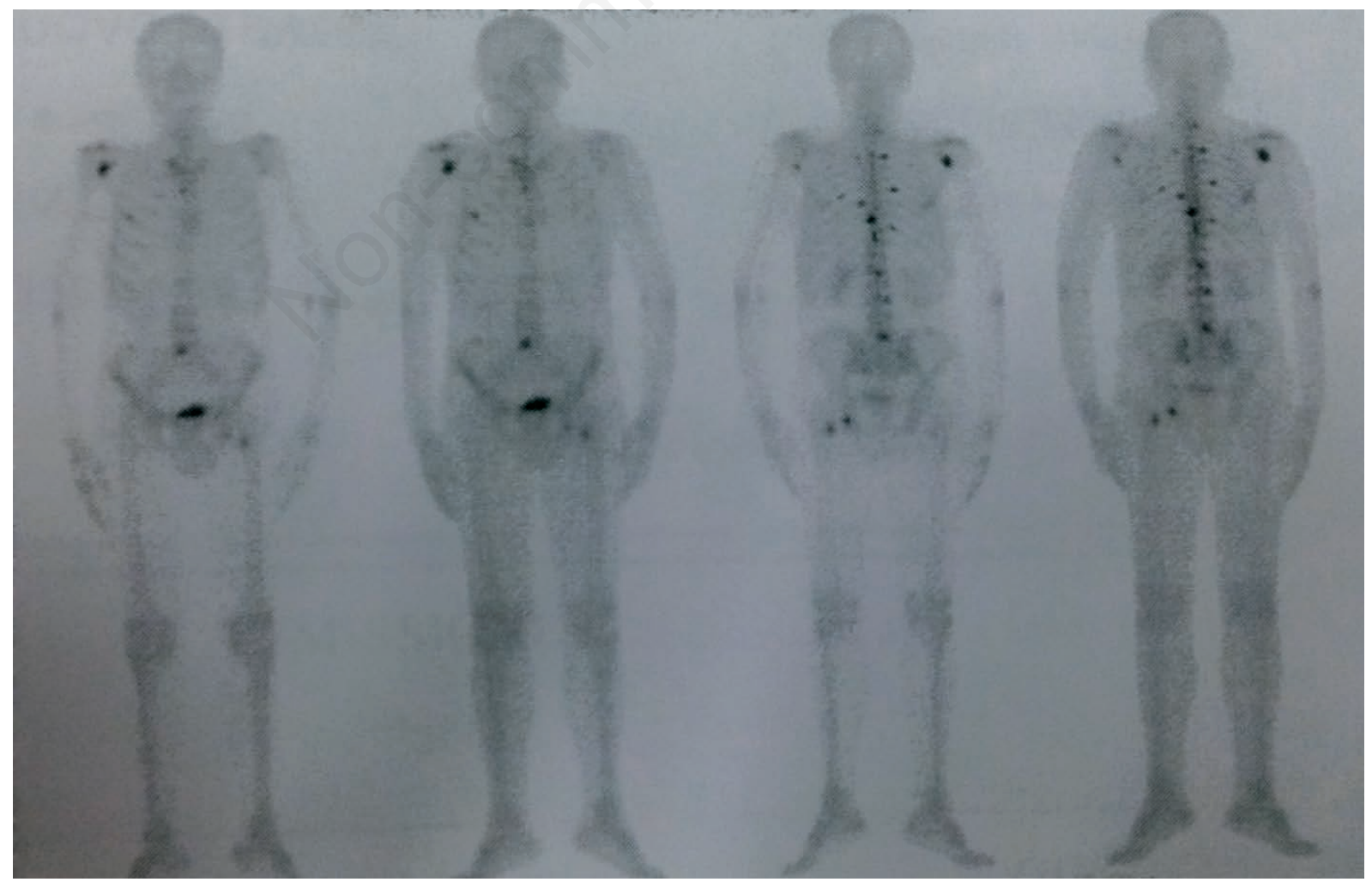

Figure 2. Bone scintigraphy. 


\section{References}

1. Adler Y, Charron P, Imazio M, et al. 2015 ESC Guidelines for the diagnosis and management of pericardial diseases. Eur Heart J 2015;36: 2921-64

2. Imazio M, Demichelis B, Parrini I, et al. Relation of acute pericardial disease to malignancy. Am J Cardiol 2005;95:1393-4.

3. Imazio M, Cecchi E, Demichelis B, et al. Indicators of poor prognosis of acute pericarditis. Circulation 2007;115:2739-44.

4. Imazio M. Contemporary management of pericardial diseases. Curr Opin Cardiol 2012;27:308-17.

5. James ND, Sydes MR, Clarke NW, et al. Addition of docetaxel, zoledronic acid, or both to first-line long-term hormone therapy in prostate cancer (STAMPEDE): survival results from an adaptive, multiarm, multistage, platform randomised controlled trial. Lancet 2016;387:1163-77.
6. Imazio M, Adler Y. Management of pericardial effusion. Eur Heart J 2013;34:1186-97.

7. Imazio M, Spodick DH, Brucato A, et al. Controversial issues in the management of pericardial diseases. Circulation 2010;121:916-28.

8. Corey GR, Campbell PT, Van Trigt P, et al. Etiology of large pericardial effusions. Am J Med 1993;95:209-13.

9. Conway N, Hutchison S. Malignant pericardial effusion in a patient with prostate adenocarcinoma. BMJ Case Rep 2012;2012:bcr0120125570.

10. Laham RJ, Cohen DJ, Kuntz RE, et al. Pericardial effusion in patients with cancer: outcome with contemporary management strategies. Heart 1996;75:67-71.

11. Shariff SMN, Karthik S. A rare case of cardiac tamponade due to metastatic cancer of the prostate. SMJ 2006;51:57.

12. Ristić AD, Pankuweit S, Maksimović R, et al. Pericardial cytokines in neoplastic, autoreactive, and viral pericarditis. Heart Fail Rev 2013;18:345-53. 